\section{Survey of patients from an inner-London health authority in medium secure psychiatric care ${ }^{\dagger}$}

\author{
PAUL LELLIOTT, BERNARD AUDINI and RICHARD DUFFETT
}

There is a high correlation between the use of medium secure beds and levels of social deprivation within the population, particularly the rate of unemployment (Guite $\&$ Field, 1998). In keeping with this, the rate of use of medium secure beds per unit of population in Greater London in 1996 was nearly twice that of England and Wales as a whole. At this time, London made heavy use of provision outside the National Health Service (NHS), accounting for about half of the use of independent-sector beds (Guite \& Field, 1998). A review, commissioned by Lambeth, Southwark and Lewisham Health Authority (LSLHA) in south-east London, provided an opportunity to conduct a census of all people from the LSLHA 730000 catchment population who were accommodated in any form of medium secure provision at the end of 1997.

\section{METHOD}

The aims of the study were:

(a) to describe this group of patients;

(b) to compare those accommodated in NHS medium secure facilities with those in independent units; and

(c) to compare patients from different ethnic groups, in particular to compare Black patients with White patients.

\section{Definitions and criteria for inclusion}

The definition of a medium secure placement used was: 'the placement of a patient who is unsuitable for care within general psychiatric services and who requires specialist and/or secure care, but not at a level provided by a high security hospital'. To be included, patients had to meet all of the following criteria:

(a) the commissioning of their care was the responsibility of LSLHA; (b) resident on a census day in August 1997;

(c) not on a local NHS low-security unit;

(d) not resident in a high-security hospital; and

(e) aged 18 years or over.

The settings ranged from highly staffed units with 'air-lock' entrances, to lowerstaffed facilities which were unlocked. The latter were all part of an integrated forensic service. Most patients in this type of facility had been transferred from a more secure environment as part of a process of rehabilitation back to local general psychiatric services.

\section{Patient identification}

The list provided by LSLHA identified patients in 15 separate locations (three local NHS medium secure units and 12 units managed by the independent sector). All units were contacted, and 11 were visited. In a few cases the list was found to be incorrect and, in many more instances, to be incomplete. As a result a number of additional patients were identified.

\section{Data collection schedules}

A schedule used to describe people resident in a wide range of types of mental health accommodation (Lelliott et al, 1996) was adapted to take account of the particular characteristics of the study population. The revised schedule collected data about referral (date and source); demographic characteristics (age, gender, marital status, ethnicity, employment status, residential status prior to entry to the facility); forensic history (contact with criminal justice system: number of arrests, time spent in prison, number of prison sentences following conviction); offending behaviour (rated under one or more of 12 categories); past and recent aggression (index offence and past aggressive acts, rated on five-point scales derived from Gunn \& Taylor, 1976; aggression in month preceding assessment, rated on the Overt Aggression Scale of Yudofsky et al, 1986); risk if discharged to independent living; psychiatric history (time since first contact, number and total duration of admissions, diagnosis); problems associated with behaviour, symptoms, impairment and social function in the month preceding assessment (items 1-10 of the Health of the Nation Outcome Scales (HoNOS; Wing et 
al, 1996); these items are all rated on fivepoint scales; additionally, daily living skills and interpersonal relationships were rated on four-point scales).

\section{Data collection methods}

Most data were collected between August and October 1997. Information was gathered by a combination of studying case notes and interviewing keyworkers or other senior ward staff. Data were collected by B.A. and R.D. during visits to the units; for the eight patients in units not visited, data were collected during a telephone interview with the keyworker.

\section{Statistical analyses}

Less than $4 \%$ of data items were missing. These were excluded from relevant analyses. The large number of items relating to clinical, social and behavioural variables was reduced. The grouping of variables was informed by a previous analysis of a larger cohort of people in mental health residential facilities (Lelliott et al, 1996). Scores on these composite variables were used to compare groups. Differences between groups were assessed using independent $t$-tests and chi-squared tests.

\section{RESULTS}

A total of 183 patients were identified as meeting study criteria. A few data items were missing for some patients: valid percentages are given for all results presented, i.e. missing data were excluded.

\section{Characteristics of the whole cohort}

The patients predominantly were men (87\%, $n=159)$, had been unemployed prior to admission (93\%, $n=164)$ and were single, i.e. did not have a stable relationship with a partner $(92 \%, n=167)$. The mean age was 36 years (range 17-64 years). Only $36 \%(n=65)$ of the cohort were categorised as White (6 of whom were Irish). More than half $(57 \%, n=103)$ were Black. The latter group comprised 78 Black-Caribbean (43\% of the total); 20 Black-African (11\%); 2 Somali; and 3 'other Black'. The remainder were from other ethnic groups (7\%, $n=12)$.

Most of the cohort had been diagnosed as having a psychotic illness: schizophrenia, schizophreniform disorder, schizoaffective disorder or bipolar disorder (93\%, $n=163)$; and $10 \%(n=18)$ had a primary or secondary diagnosis of a personality disorder. Only five patients were not detained under a Section of the Mental Health Act 1983; $62 \%(n=114)$ were detained under Part III and $45 \%(n=83)$ were on a restriction order. The mean length of stay of patients in their current placement was 1.5 years ( $95 \%$ confidence interval for the difference, -0.20 to 0.28 ).

Sixty-seven patients $(37 \%)$ had been admitted from a court or a prison, 15 (8\%) from high-security hospitals and 31 $(17 \%)$ from other medium-security hospitals. The remainder had been admitted either directly from the community $(4 \%$, $n=8)$ or from general psychiatric services (32\%, $n=59)$. For about one-quarter $(n=43)$, no specific behaviour or offence was recorded as having led to their index admission. (However, information about offending behaviour/index offence does not necessarily accord with a criminal conviction for that offence. This information was provided by staff in the secure units and was based on the information contained in the clinical records.) The remainder had committed a range of offences: murder, manslaughter or attempted murder $(7 \%$, $n=13)$; sexual offence ( $12 \%, n=22)$; arson (8\%, $n=15)$; threats to kill, actual or grievous bodily harm or assault or wounding $(42 \%, n=76)$; criminal damage, theft or other offence $(19 \%, n=35)$. Some had committed more than one category of offence.

When previous offending behaviour was taken into account, only $7 \%(n=12)$ had not committed at least one of these offences in the past. About one-third $(n=58)$ had committed at least one act of severe violence ('victim died or life was seriously endangered - includes rape and attempted rape') and a further half $(n=90)$ at least one act of moderately severe violence ('an attack which resulted in serious injury or extensive damage to property which could have resulted in threat to life'). Consistent with this, as a group the patients had had extensive contact with the criminal justice system: $86 \% \quad(n=146)$ had been arrested previously, and 39\% $(n=72)$ had been arrested five or more times; $86 \% \quad(n=144)$ had spent time in prison, either on remand or as a sentenced prisoner; $51 \%(n=86)$ had spent more than 6 months in prison.

Most patients had also had extensive and prolonged contact with mental health services; $56 \%(n=101)$ had more than five previous admissions and for $50 \%(n=90)$ the first contact with psychiatric services had been more than 10 years previously.

The patients' recent mental health and behaviour were assessed using the ten HoNOS items and the five factors derived from variables about the patients' mental health, social function and behaviour during the preceding months (Table 1). For HoNOS items a score of 1 indicates a minor 'subclinical' problem, and for the five factors it indicates a mild problem. Mean scores on the Overt Aggression Scale (range $0-4)$, rated over the previous month, were low (verbal aggression 0.94; aggression directed at property 0.36 ; directed at self 0.10 ; directed at another person 0.45). However, in the opinion of staff making the ratings, $128(70 \%)$ of the patients would have posed a medium or severe risk to others were they to be discharged to independent living at the time of the assessment.

\section{Comparison between residents of NHS and independent sector facilities}

Eighty-eight patients (48\%) were in independent-sector facilities. These patients had slightly greater lengths of stay than those in NHS units (1.7 v. 1.4 years). This difference was not significant and was largely accounted for by a few patients in the independent sector who had very long durations of stay (six of these patients had stays of more than 5 years, compared with none in an NHS facility). There were no differences in terms of age, gender, ethnic group, diagnosis, or previous contact with either the criminal justice system or mental health services.

The route into the units differed for the two groups of patients. Patients in the independent sector were less likely to have been referred directly from the criminal justice system (court or prison) or from a high-security hospital than those in NHS medium secure facilities $(37 \% v$. $63 \% ; \chi^{2}=7.6, P<0.01$ ), and much more likely to have been admitted from general psychiatric services $(48 \% \quad v$. $19 \%$; $\left.\chi^{2}=16.6, P<0.001\right)$. Consistent with this, independent-sector patients were less likely to be detained under Part III of the Mental Health Act 1983 (49\% v. 73\%; $\chi^{2}=10.9$, $P<0.001)$ or to be on a restriction order (33\% v. 57\%; $\left.\chi^{2}=10.5, P<0.01\right)$.

The index admission for patients in the independent sector was more likely to be 
Table I Scores for Health of the Nation Outcome Scales (HoNOS) and compound variables for clinical, behavioural and social function variables. Whole cohort and comparison of White $v$. Black patients and of patients in NHS v. independent-sector units (Ind.)

\begin{tabular}{|c|c|c|c|c|c|}
\hline & \multirow[t]{2}{*}{ All $(n=183)$} & \multicolumn{2}{|c|}{ Ethnicity } & \multicolumn{2}{|c|}{ Setting } \\
\hline & & White $(n=65)$ & Black $(n=103)$ & NHS $(n=95)$ & Ind. $(n=88)$ \\
\hline \multicolumn{6}{|l|}{ HoNOS items } \\
\hline Overactive and aggressive behaviour & 1.02 & 1.33 & $0.90 *$ & 0.84 & $\mathrm{I} .24^{* *}$ \\
\hline Self-harm & 0.11 & 0.22 & $0.09 * *$ & 0.11 & 0.12 \\
\hline Alcohol or drug abuse & 0.36 & 0.44 & 0.33 & 0.37 & 0.35 \\
\hline Cognitive problems & 0.61 & 0.54 & 0.63 & 0.51 & $0.73 *$ \\
\hline Physical problems & 0.47 & 0.60 & 0.43 & 0.49 & 0.45 \\
\hline Hallucinations/delusions & 1.28 & 1.49 & 1.22 & 1.27 & 1.33 \\
\hline Depressed mood & 0.73 & 0.97 & 0.58 & 0.74 & 0.73 \\
\hline Other mental or behavioural problems & 1.13 & 1.38 & $\mathrm{I} .03 *$ & 1.06 & $\mathrm{I} .24 *$ \\
\hline Relationship problems & 1.17 & 1.32 & $1.14 *$ & 1.13 & 1.24 \\
\hline Problems with living skills & 1.05 & 1.19 & $0.97 *$ & 1.12 & 0.99 \\
\hline Total of 10 HoNOS items & 7.93 & 9.49 & 7.19* & 7.59 & 8.44 \\
\hline \multicolumn{6}{|l|}{ Compound variables } \\
\hline Symptoms of mental illness & 0.96 & 1.14 & 0.87 & 0.88 & 1.06 \\
\hline Affective symptoms & 0.66 & 0.86 & $0.54^{* *}$ & 0.64 & 0.70 \\
\hline Vulnerability & 0.95 & 1.13 & 0.84 & 0.81 & $1.12 * *$ \\
\hline Activities of daily living & 0.73 & 0.86 & $0.62^{* *}$ & 0.64 & 0.80 \\
\hline Social interaction & 0.66 & 0.68 & 0.65 & 0.65 & 0.68 \\
\hline
\end{tabular}

Significance levels independent $t$-tests: $* P<0.05, * * p<0.01$.

due to a behaviour that was non-violent $\left(28 \% v .13 \%, \chi^{2}=6.1, P<0.05\right)$ and less likely to be due to an act of severe violence $\left(20 \% v .35 \% ; \chi^{2}=5.0, P<0.05\right)$. However, $73 \%(n=63)$ of independent-sector patients had committed at least one act of moderate or severe violence at some time in their lives: this compares with $86 \%(n=79)$ of NHS patients.

Independent-sector patients were rated as more severe on a number of clinical, social and behavioural items, including overactive and aggressive behaviour (Table 1). However, these differences, although significant in statistical terms, were probably too small to be meaningful in practice.

\section{Comparison between Black and White patients}

For the purpose of these comparisons, patients categorised as Irish and 'other White' were included with those categorised as White (English, Scottish or Welsh). This gave a total of 65 patients. The Black patients were slightly younger than the White patients (34 years $v$. 38 years; $t$-test, $P<0.05)$. A higher proportion had a diagnosis of a psychotic disorder, including schizophrenia, schizophreniform disorder, schizoaffective disorder and bipolar disorder $\left(98 \% \quad v .85 \% ; \chi^{2}\right.$ corrected for continuity $=8.2, P<0.01$ ). All seven patients with a primary diagnosis of personality disorder were White. There was no significant difference between the Black and White patients in terms of previous contact with the criminal justice system or with mental health services.

The two groups were also similar in source of referral to a medium secure setting (i.e. from court, prison or a highsecurity hospital versus other psychiatric services); length of stay in a medium secure setting; and in the proportion detained under the Mental Health Act. There was no significant difference between Black and White patients in terms of the index offence or behaviour.

When considering life-time history, although White patients were more likely to have committed the most severe acts of violence ('victim died or life was seriously endangered: includes rape and attempted rape': $\left.42 \% v .27 \% ; \chi^{2}=4.1, P<0.05\right)$, this difference was not apparent when the top two categories of aggression were combined (severe violence and moderate severe violence: $83 \% v .80 \% ; \chi^{2}=0.2$, NS).

In statistical terms, Black patients were rated as significantly less severe on a number of the clinical, social and behavioural variables (Table 1). However, these differences were small, and probably not meaningful in clinical terms.

\section{DISCUSSION}

The cross-sectional nature of this survey does not allow for examination of either the flow of patients into and through medium secure units, or the process by which decisions are made to admit or not to admit. Also, it results in a cohort that overrepresents people with long stays. However, it does provide a clear 'snapshot' of the distribution of patients, from a discrete geographical area, across NHS and independent-sector provision.

\section{NHS does not meet the population's need for medium secure care}

Medium secure psychiatric units were intended to meet the needs of three main groups: those who would otherwise be housed in overcrowded high-security hospitals; those admitted through the courts; and 'difficult-to-manage' patients cared for by general psychiatric services. Although it was recommended in the 
mid-1970s that 2000 medium secure beds were required (Department of Health and Social Security, 1974; Home Office \& Department of Health and Social Security, 1975), by the end of 1996 there were still only about 1200 beds managed by the NHS (Guite \& Field, 1998). The shortfall has been met, at least in part, by the private sector, which at the end of 1995 provided about 400 such beds (Guite \& Field, 1998).

The census is consistent with a survey of all patients in NHS medium secure units in 1991 , which found that $80 \%$ of patients had been admitted from a prison or highsecurity hospital (Murray, 1996). In this London health authority, index 'offence' and route of referral were the main factors that differentiated patients in NHS units from those in the independent sector. These two factors are likely to be connected. However, the findings need to be interpreted cautiously. It is possible that NHS units do provide for brief admissions of people referred from general psychiatric services; such people would be underrepresented in the study cohort. The hypothesis that access to NHS medium secure care is determined more by the source of referral than by clinical need could only be tested by a longitudinal study of consecutive referrals and admissions.

Prioritisation is necessary when bed numbers are insufficient to meet the need. The survey illustrates the extent to which this is the case for the catchment population of LSLHA. Based on the NHS Trust manual of accounts estimate of a cost of $£ 247$ per day for a medium secure bed in 1996-1997, the 90 beds occupied in the independent sector would have cost LSLHA about $£ 8$ million per year-money that might have been invested in local services. The cost is not just financial. Patients admitted to distant independent-sector hospitals will have less contact with their families and other community supports. They are also likely to experience a discontinuity in care when they are discharged back to the local area.

The Government has recently announced funding for an additional 221 medium secure places for England and Wales (Department of Health, 1999). The results of this survey suggest that the number might be insufficient (none of the beds funded by this new money is in Lambeth, Southwark or Lewisham) to reduce significantly the dependence on the independent sector.

\section{CLINICAL IMPLICATIONS}

- In one inner-London health authority, 90 patients were accommodated in independent-sector medium secure facilities - nearly as many as those in National Health Service (NHS) units.

Patients in independent-sector medium secure facilities were more likely to have been referred from general psychiatric services than those in NHS medium secure units.

- There were three times more Black patients in medium secure care than would be expected from the make-up of the population. However, these patients differed little from White patients in terms of their histories, clinical state, behaviour or social functioning.

\section{LIMITATIONS}

- The study was cross-sectional. It therefore did not allow detailed exploration of patient flows into and through medium secure care. Also, patients with short lengths of stay were underrepresented in the study cohort.

Data were collected by or from the patients' keyworkers and not by independent, trained researchers.

The assignment of ethnicity relied on identification by keyworker or on that recorded in psychiatric case notes.

PAUL LELLIOTT, MRCPsych, Director, BERNARD AUDINI, MSc, Research Fellow, RICHARD DUFFETT, MRCPsych, Research Fellow, Royal College of Psychiatrists' Research Unit, London, UK

Correspondence: Dr Paul Lelliott, Royal College of Psychiatrists' Research Unit, 6th Floor, 83 Victoria Street, London SWIH OHW, UK

(First received 17 January 2000, final revision 5 June 2000, accepted 9 June 2000)

\section{Increasing need for medium secure care in the LSLHA area}

According to Guite \& Field (1998), in 1995 the LSLHA had the highest rate of use of medium secure beds in London (13 per 100000 population) and four times the average for England and Wales (3.1 per 100000$)$. This census, conducted 2 years later, identified twice as many patients in this type of facility (25 per 100 000). Although some of this difference may be due to better case identification, it probably also reflects a real and substantial increase in the use of medium secure beds. Indeed, it was concern about this that led the health authority to commission the review. The causes of this increase can only be speculated about: they may include a more risk-averse culture in general psychiatric services, and political and organisational changes resulting in more diversions from custody and high-security care.

Much of Lambeth, Southwark and Lewisham is a deprived inner-city area. Two of the boroughs within the LSLHA catchment area (Lambeth and Southwark) are among the six most deprived districts in England (Johnson et al, 1998). There is some evidence that the more severe forms of mental illness are concentrated in such deprived inner-city areas (Glover et al, 1999). Also, a high proportion of the residents are from ethnic minority groups. Black-Caribbean people, who comprise $19 \%$ of the LSLHA population compared with about $2 \%$ for England and Wales, are greatly overrepresented in medium secure units (Jones \& Berry, 1986; Murray, 1996; Maden, 1999). 


\section{Differences between ethnic groups}

The identification of ethnicity relied on that recorded in the psychiatric case notes, and transcribed by the patients' keyworkers. The design of the study did not permit separate verification. With this caveat, the findings of this cross-sectional survey are very similar to those of a longitudinal cohort study also conducted in south London (Maden et al, 1999) in that:

(a) the point prevalence of Black patients was three times as high as the proportion of Black people in the population;

(b) Black patients were slightly younger than White patients;

(c) Black patients were less likely to have a primary diagnosis of personality disorder; and

(d) there were few differences between Black and White patients in terms of previous offending or psychiatric history.

As Maden et al concluded from their cohort, the results of this study do not help to explain the overrepresentation of Black people in medium secure psychiatric settings. Whatever the cause, Black patients appear to be similar to White patients on many of the variables that might be expected to indicate a need for care at that level of security.

\section{REFERENCES}

Department of Health (1999) Government Increases Number of Secure Beds for Mental Health Patients. Press release, 14 July 1999.

Department of Health and Social Security (1974) Report on Security in Special Hospitals (Glancy Report). London: HMSO.

Glover, G. R., Leese, M. \& McCrone, P. (1999) More severe mental illness is concentrated in deprived areas. British Journal of Psychiatry, 175, 544-548.

Guite, H. \& Field, V. (1998) Services for mentally disordered offenders. In London's Mental Health (eds S. Johnson, S. Ramsay, G. Thornicroft, et al), pp. 99-II7. London: King's Fund.

Gunn, J. \& Taylor, P. (1976) Psychopathic personality: conceptual problem. Psychological Medicine, 6, 631-634.

Home Office \& Department of Health and Social Security (1975) Interim Report of the Committee on Abnormal Offenders (Butler Report). London: HMSO.
Johnson, S., Ramsay, R. \& Thornicroft, G. (1998) Londoners' mental health needs: the sociodemographic context. In London's Mental Health (eds S. Johnson, S Ramsay, G. Thornicroft, et al), pp. 15-32. London: King's Fund.

Jones, G. \& Berry, M. (1986) Regional secure units: the emerging picture. In Current Issues in Clinical Psychology IV (ed. G. Edwards), pp. III-II9. London: Plenum.

Lelliott, P., Audini, B., Knapp, M., et al (1996) The mental health residential care study: classification of facilities and description of residents. British journal of Psychiatry, 169, 139-147.

Maden, A. (1999) Forensic psychiatry. In Ethnicity: An Agenda for Mental Health (eds D. Bhugra \& V. Bahl), pp. 15I-157. London: Gaskell.

\section{_, Friendship, C., McClintock, T., et al (1999)}

Outcome of admission to a medium secure psychiatric unit. Role of ethnic origin. British Journal of Psychiatry, 175, 317-321.

Murray, K. (1996) The use of beds in NHS medium secure units in England. Journal of Forensic Psychiatry, $\mathbf{7}$, 504-524.

Wing, J. K., Curtis, R. H. \& Beevor, A. S. (1996) HoNOS: Health of the Nation Outcome Scales. Report on Research and Development: July 1993-December 1995. London: Royal College of Psychiatrists.

Yudofsky, S., Silver, J., Jackson, W., et al (1986) The Overt Aggression Scale for the objective rating of verbal and physical aggression. American Journal of Psychiatry, 143, 35-39. 